\title{
Associations of vacation time with lifestyle, long-term mortality and health-related quality of life in old age : The Helsinki Businessmen Study
}

\section{Strandberg, T. E.}

2017-07

Strandberg , T E , von Bonsdorff , M , Strandberg , A , Pitkala , K \& Raikkonen , K 2017 , ' Associations of vacation time with lifestyle, long-term mortality and health-related quality of life in old age : The Helsinki Businessmen Study ' , European Geriatric Medicine , vol. 8 , no. 3 , pp. 260-264 . https://doi.org/10.1016/j.eurger.2017.03.003

http://hdl.handle.net/10138/304255

https://doi.org/10.1016/j.eurger.2017.03.003

publishedVersion

Downloaded from Helda, University of Helsinki institutional repository.

This is an electronic reprint of the original article.

This reprint may differ from the original in pagination and typographic detail.

Please cite the original version. 


\title{
Research paper
}

\section{Associations of vacation time with lifestyle, long-term mortality and health-related quality of life in old age: The Helsinki Businessmen Study}

\author{
T.E. Strandberg ${ }^{\text {a,b,* }}$, M. von Bonsdorff ${ }^{c, d}$, A. Strandberg ${ }^{\text {a }}$, K. Pitkälä ${ }^{a}$, K. Räikkönen ${ }^{\text {e }}$ \\ a University of Helsinki, Clinicum, and Helsinki University Hospital, Helsinki, Finland \\ ${ }^{\mathrm{b}}$ University of Oulu, Center for Life Course Health Research, Oulu, Finland \\ ${ }^{\mathrm{c}}$ Gerontology Research Center and Department of Health Sciences, University of Jyväskylä, Finland \\ ${ }^{\mathrm{d}}$ Folkhälsan Research Center, Helsinki, Finland \\ ${ }^{\mathrm{e}}$ Institute of Behavioural Sciences, University of Helsinki, Helsinki, Finland
}

\section{A R T I C L E I N F O}

\section{Article history:}

Received 3 January 2017

Accepted 6 March 2017

Available online 27 March 2017

\section{Keywords:}

Holidays

Lifestyle

Mortality

Quality of life

Self-rated health

Vacation

\begin{abstract}
A B S T R A C T
Introduction: There are few longitudinal studies of relationships between vacation and later health outcomes. We studied these during a 26-year follow-up of the Helsinki Businessmen Study.

Methods: In 1974, at mean age of 47 years, 2741 members of a cohort of executives and businessmen born 1919-1934 were clinically examined and reported their annual vacation time (dichotomized $>21$ [ $n=2001]$ vs. $\leq 21$ days $[n=740]$ ), self-rated health (SRH) and perceived physical fitness using a five-step scale. In old age in 2000 (mean age 73 years), the survivors filled in the RAND-36/SF-36 health-related quality of life (HRQoL) questionnaire. Mortality between 1974 and 2000 was retrieved from national registers.

Results: At baseline, shorter vacation was associated with longer work time, higher BMI, more coffee consumption and worse SRH. During the 26-year follow-up, 778 men out of 2741 (28.4\%) had died. Shorter annual vacation was associated with higher mortality with curves starting to diverge after 18 years of follow-up, (fully adjusted hazard ratio $1.29,95 \%$ confidence interval $1.08-1.55, P=0.005$ ). In old age, shorter vacation in midlife was tentatively associated with worse general health.

Conclusions: Shorter vacation time in midlife was associated with characteristics related to lifestyle and with worse perceived health status, and predicted mortality up to old age in men.
\end{abstract}

(c) 2017 Elsevier Masson SAS and European Union Geriatric Medicine Society. All rights reserved.

\section{Introduction}

Short-term studies of vacation, health, well-being and stress have suggested that - as a recovery process from work - vacation does have positive effects in the individual, but the effects are not large and do not necessarily last long [1-3]. However, vacation is usually a repeating process and cumulative effects may be important during long-term and differ from short-term effects.

In contrast to long working hours [4-6], the associations of vacation with serious health outcomes, such as mortality, have received much less attention. Reflecting this, the search in PubMed with keywords work and mortality produced $>20000$ hits, while for vacation and mortality or holiday* and mortality produced less

\footnotetext{
* Corresponding author at: University of Helsinki, Haartmaninkatu 4, PO Box 340, FIN-00029 Helsinki, Finland. Tel.: +358 406724533.

E-mail address: timo.strandberg@oulu.fi (T.E. Strandberg).
}

than 500 ones. Moreover, to our knowledge there are only two longitudinal studies about vacation in relation to morbidity or mortality $[7,8]$, their conclusion being that longer vacation time may be good for health. In the large Multiple Risk Factor Intervention Trial (MRFIT [8]), higher frequency of annual vacations of middle-aged men was associated with a reduced risk of premature mortality in a nine-year follow-up. Because the reduction was observed especially for cardiovascular mortality, the mechanism underlying this association may be related to stressrelieving properties of vacation. However, that finding does not confirm cause and effect as men taking more vacation may have intrinsic properties to protect them [8]. Accordingly, it has been reported that there is a connection between less vacation and predisposition to psychosomatic disease [9].

In Finland, annual vacations have been stipulated in law since the 1920s, and in 1973, a four-week vacation was established as a legal right for those with more than 10 -year working history in all socioeconomic groups. In other labour market systems, 
socioeconomical status may be related to annual vacation time in that those with lower status have less possibilities to enjoy longer vacations. This is likely to confound the relationships with health outcomes [10]. This type of confounding is smaller in the Nordic countries where everyone is legally entitled to equal rights to vacation annually. This can be further reduced by exploring the associations in a socioeconomically homogeneous population such as the Helsinki Businessmen Study (HBS) cohort [11,12].

We have recently reported that longer working hours coupled with shorter sleep duration in midlife were associated with poorer physical functioning in old age [13]. In the present study we have related annual vacation time in midlife to personal characteristics, including self-rated health (SRH), mortality during a 26-year follow-up, and health-related quality of life (HRQoL) in old age.

\section{Methods}

\subsection{Participants}

The HBS cohort (original $n=3490$ ) has been described in detail earlier [11-13]. The present analytic subcohort $(n=2741)$ consisted of white men born between 1919 and 1934 (age range 40-55 years), and belonging to the highest social strata with similar socioeconomic and working status. Data on annual vacation time in 1974 (exact work history was not available, but it can be assumed that all participants were eligible for the at least 4-week vacation stipulated by the law), and follow-up outcome data through the year 2000 were available. Of the 2741 men, 2712 (99.1\%) reported working at least 30 h per week, and 2203 (80.5\%) were clinically healthy (no chronic diseases or regular medications) at baseline. Of the latter, 600 (27.2\%) participated in a primary prevention trial between 1974 and 1980 [8]. Details of the various groups in 1974 have been presented in the cohort profile [12]. To control for the possibility that group assignment (clinical status/participation in the trial) would interfere with vacation time and follow-up outcomes, group assignment was adjusted for in the analyses. After 26 years of follow-up in 2000, the survivors ( $n=1983$, mean age 73 years, age range 66 to 81 years) were sent a postal questionnaire. The questionnaire was re-sent once for nonrespondents, and in all 1669 (84.2\%) men responded. The followup of the HBS has been approved by the ethical committee of the Department of Medicine, Helsinki University Central Hospital, and the study is registered as ClinicalTrials.gov identifier: NCT02526082.

\subsection{Measures}

In 1974 the cohort members were asked what was their annual total vacation time (in days), how many hours per week they work and how many hours they sleep during a week. We did not have information of the number of vacation periods or the timing of these periods, but in the 1970s the bulk of vacation was usually taken in one period during summer months in Finland. Vacation time was dichotomized into shorter ( $\leq 21$ working days of vacation per year) vs. longer ( $>21$ working days of vacation per year). Reason for dichotomizing was that vacation time was skewed (21 days was the cutpoint of lowest quartile) and because annual vacation time was legally stipulated to be four weeks since 1973 , three weeks or less of vacation could be considered unusually short among men in the highest social strata. Work and sleep duration were used as continuous variables in the analyses.

In 1974, the cohort members were also asked about current smoking status (yes vs. no), alcohol and coffee consumption, and self-rated health (SRH) and self-rated physical fitness with a Likerttype five-step scale (answering alternatives were very good, fairly good, average, fairly poor and very poor), of which the two latter ones were coded into one category "poor" because only 5 men were in the very poor category [14]). Clinical investigations in 1974 included measurements of cardiovascular disease (CVD) risk factors including current body mass index (BMI) and also recalled weight at age 25 years, as described earlier [8]. Coronary heart disease risk score for hard criteria was calculated according to Keys et al. [15].

\subsection{Follow-up 1974-2000}

Mortality was comprehensively followed up from the Finnish Population Information System Register Centre through 31 December 2000, and causes of deaths were retrieved from Statistics Finland. According to these registers, the assessment of the vital status is very reliable for people having their permanent place of residence in Finland (over 95\% of the present cohort) irrespective whether they die in Finland or abroad. Moreover, the assessment of the vital status is also quite reliable for Finnish citizens living permanently abroad. Causes of deaths were divided in broad categories: coronary, other CVD, cancer, violent (accidents and suicides), and other causes. The postal questionnaire in 2000 included items about social factors (retirement, marriage status), anthropometric measures, medication, and lifestyle factors (e.g. alcohol consumption, smoking). In addition, the Finnish version of the RAND-36-Item Health Survey 1.0 (practically identical to Short Form [SF]-36, and validated in the Finnish population) was embedded into the questionnaire [16]. A comorbidity index was calculated from the responses, taking into account the number and severity of comorbid conditions [17].

The RAND-36 survey, used for assessing HRQoL, comprises eight domains: Physical functioning (PF), Role limitations caused by physical health problems (RP), Role limitations caused by emotional problems (RE), Vitality (VT), Mental health (MH), Social functioning (SF), Bodily pain (BP), and General health (GH). Scores range from zero to 100 , with 100 representing the best level of functioning or wellbeing. A difference of three to five points in the RAND-36 domains is considered to be clinically important [18].

A flow chart of the analyses is shown in Fig. 1.

\subsection{Statistical analyses}

$T$-tests, nonparametric tests, and analyses of covariance (ANCOVA) were used where appropriate to compare continuous variables (mean with standard deviation [SD]), logarithmic transformation where appropriate) across vacation time groups. Vacation time was highly skewed and the lowest quartile $-\leq 21$ working days of vacation - was taken as cutpoint (vacation time was also tested as a continuous variable). Chi-square and trend tests were used to compare proportions. Kaplan-Meier curves and Cox regression analysis with various adjustments (also to emulate those used in MRFIT [8]) were used to assess the relationship between vacation time and mortality during follow-up. Automated stepwise selection procedures were not used. The results are presented as hazard ratios (HR) with their $95 \%$ confidence intervals (CI). In statistical analyses two-sided $P$-values are given. The statistical software NCSS (version 2004, www.ncss.com, Kaysville, UT, USA) was used for the statistical analyses.

\section{Results}

In 1974,740 men reported having $\leq 21$ working days of vacation annually, Table 1 shows clinical and laboratory characteristics according to vacation time. For men in the short vacation time group the average length of annual vacation was less than half of that of the men in the longer vacation time group (14.8 vs. 32.0 days, respectively), and weekly work time was six hours 
1964-1973 Start of the Helsinki Businessmen Study: $\mathbf{3 4 9 0}$ healthy men, businessmen and executives born 1919-1934, were clinically investigated

1974 Baseline of the current analyses: 2741 men were clinically investigatedand they reported annual vacation time, weekly work and sleep time, and self-rated health and physical fitness. $\mathbf{8 0 . 5 \%}$ were clinically healthy without chronic diseases or medications

1974-2000 Mortality follow-up from national registeries:

778 men $(28.4 \%)$ died between baseline and year 2000

Of the 1983 survivors ( $72.3 \%$ of baseline), 1669 men $(84.2 \%)$ responded to a postal questionnaire survey: questions about health, diseases, and retirement;

RAND-36 (SF-36) health-related quality of life instrument was embedded in the questionnaire.

Fig. 1. Flow chart of the Helsinki Businessmen Study and the present analyses.

Table 1

Baseline characteristics in 1974 (means or medians and standard deviation unless stated otherwise) according to annual vacation time.

\begin{tabular}{|c|c|c|c|}
\hline \multirow[t]{2}{*}{ Variable in $1974^{\mathrm{a}}$} & \multicolumn{3}{|l|}{ Vacation } \\
\hline & $>21$ days, $n=2001$ & $\leq 21$ days, $n=740$ & $P$-value for difference between groups \\
\hline Age, yr & $47.9(4.2)$ & $47.6(3.9)$ & 0.04 \\
\hline Vacation time, days/year & $32.0(10.3)$ & $14.8(5.8)$ & $<0.001$ \\
\hline Work time, hours/week & $46.1(8.8)$ & $52.1(11.2)$ & $<0.001$ \\
\hline Sleep time, hours/week & $50.4(6.6)$ & $50.1(6.4)$ & 0.07 \\
\hline BMI at 25 years of age, $\mathrm{kg} / \mathrm{m}^{2}(n=1683)$ & $22.7(2.1)$ & $22.9(2.3)$ & 0.06 \\
\hline Weight gain from 25 years to $1974, \mathrm{~kg}$ & $9.9(8.4)$ & $10.3(8.5)$ & 0.29 \\
\hline BMI, $\mathrm{kg} / \mathrm{m}^{2}$ & $25.8(2.7)$ & $26.2(3.0)$ & 0.016 \\
\hline Smokers, $n(\%)$ & $561(28.0)$ & $212(28.6)$ & 0.75 \\
\hline Alcohol consumption, g/week & $161.0(153.8)$ & $171.0(162.6)$ & 0.41 \\
\hline Coffee consumption, cups/day & $4.0(2.4)$ & $4.4(2.6)$ & $<0.001$ \\
\hline \multicolumn{4}{|l|}{ Blood pressure, $\mathrm{mmHg}$} \\
\hline Systolic & $143(19)$ & $143(20)$ & 0.41 \\
\hline Diastolic & $92(11)$ & $91(11)$ & 0.20 \\
\hline Resting heart rate, beats/min & $64.2(10.9)$ & $64.0(10.7)$ & 0.96 \\
\hline \multicolumn{4}{|l|}{ Serum lipids, $\mathrm{mmol} / \mathrm{L}$} \\
\hline Cholesterol & $6.3(1.1)$ & $6.2(1.0)$ & 0.62 \\
\hline Triglycerides & $1.6(0.9)$ & $1.6(0.9)$ & 0.61 \\
\hline \multicolumn{4}{|l|}{ Blood glucose, $\mathrm{mmol} / \mathrm{L}$} \\
\hline Fasting & $4.7(0.8)$ & $4.8(0.8)$ & 0.12 \\
\hline One-hour & $7.1(2.2)$ & $7.3(2.3)$ & 0.053 \\
\hline Keys' risk score ${ }^{\mathrm{b}}, \%$ & $2.1(1.8)$ & $2.0(1.9)$ & 0.18 \\
\hline
\end{tabular}

a Continuous variables are mean (SD).

b Includes age, smoking, cholesterol, systolic blood pressure and BMI, and is a composite risk score for coronary heart disease [14].

longer. Average age was slightly lower among men with short vacation time and they had higher BMI in midlife. No differences were observed in traditional CVD risk factors (cholesterol, blood pressure and smoking) nor alcohol consumption, whereas men with short vacation time consumed more coffee.

Self-rated health - but not self-rated physical fitness - was worse among men with short vacation time in midlife (Table 2). This difference prevailed $(P<.01)$ after adjusting for age, BMI, work time, smoking, alcohol use, and baseline group assignment.

During the follow-up through December 31, 2000, 778 men out of $2741(28.4 \%)$ had died, 247, 88, 220, 71, and 152 men because of coronary heart disease, other CVD, cancer, violence, and other causes, respectively. During the 26-year follow-up, unadjusted total mortality was higher among men with short than long vacation time ( $n=237$ [30.5\%] and $n=541$, [27.0\%], respectively, $\log$ rank $P=.012$ ). The mortality difference did not materially change and remained statistically significant $(P=.02)$ if men with fairly poor and very poor health at baseline (6.1\% of all) were excluded. However, mortality curves did not diverge until after about 18 years of follow-up (Fig. 2). Except for other CVD, causespecific mortality was higher for all causes among men with shorter vacation time, but $P$-values were $>05$ (data not shown).

In Cox analyses, adjusted for age, BMI, work time, smoking, alcohol use, SRH, and baseline group assignment, short vacation time was associated with $29 \%$ increased total mortality (HR 1.29, 95\% CI 1.08-1.55, $P=.005)$. Adjustment for age, smoking, cholesterol, diastolic blood pressure and group assignment (to emulate MRFIT) did not materially change the result (HR 1.29, 95\% 
Table 2

Self-rated health and self-rated physical fitness in 1974 according to annual vacation time.

\begin{tabular}{|c|c|c|c|}
\hline \multirow[t]{2}{*}{ Variable in 1974} & \multicolumn{3}{|l|}{ Vacation } \\
\hline & Vacation $>21$ days, $n=2001$ & Vacation $\leq 21$ days, $n=740$ & $P$-value for difference between groups \\
\hline \multicolumn{4}{|l|}{ Self-rated health } \\
\hline Very good, \% & 6.6 & 5.6 & \\
\hline Fairly good & 45.5 & 38.6 & \\
\hline Average & 42.7 & 47.6 & \\
\hline Fairly poor or very poor & 5.3 & 8.2 & $\begin{array}{l}\text { Global }<001 \\
\text { (comparing patterns of self-rated health) }\end{array}$ \\
\hline \multicolumn{4}{|l|}{ Self-rated physical fitness } \\
\hline Very good, \% & 3.9 & 3.5 & \\
\hline Fairly good & 30.0 & 28.7 & \\
\hline Average & 51.2 & 49.9 & \\
\hline Fairly poor or very poor & 15.0 & 17.9 & $\begin{array}{l}\text { Global } .43 \\
\text { (comparing patterns of self-rated physical fitness) }\end{array}$ \\
\hline
\end{tabular}

Log-rank $p=.012$

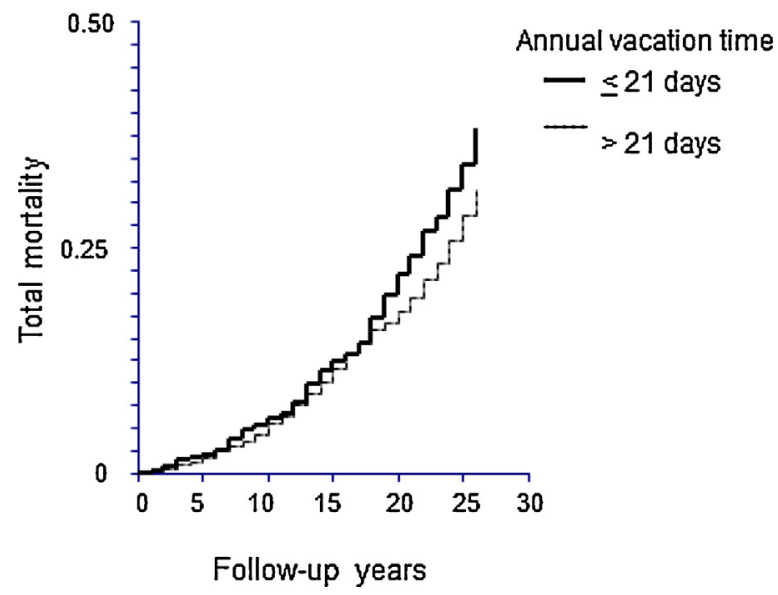

Fig. 2. Unadjusted Kaplan-Meier curves of total mortality according to baseline annual vacation time.

CI 1.04-1.60, $P=.02$ ). We also checked vacation time as a continuous variable. In adjusted Cox analyses HR per one week of more vacation was 0.95 (95\% CI $0.90-1.00, P=.07)$.

Among survivors there was no difference in comorbidity index between men with long (mean 1.5, SD 1.4) and short vacation time (mean 1.6, SD 1.5) $(P=.28$ between groups). HRQoL data of respondents in 2000 are shown in Table 3. In unadjusted comparisons, the RM score and mental summary score were lower among men with less vacation compared to men with more vacation, but adjustments attenuated the differences.
In 2000, 70 men (4.2\%) reported to be still working. Median age of retirement was 62 years (IQ range 60-64 years). Age at retirement had been $<60,60-62,63-64$, and $\geq 65$ years in 25.0, $34.3,19.6$, and $21.0 \%$ of the men, respectively. Men still working had had significantly shorter annual vacation time at baseline than retired men (23.6 days vs. 27.5 days, $P=.005$ ). The group with oldest retirement age ( $>65$ years) had the largest proportion of short vacation time at baseline $(33.7 \%$ vs. $22.1 \%$ in other groups, $P<.001)$.

\section{Discussion}

In these analyses among middle-aged men, shorter vacation time was associated with higher premature mortality during the follow-up. Although shorter annual vacation time was associated with some personal characteristics at baseline - such as longer work time and higher BMI, worse self-rated health and higher coffee consumption - the higher mortality risk was independent of these factors. In old age, men still working or retired later were characterized by shorter vacation time in midlife, but there were only tentative differences related to general health and mental HRQoL, which were worse in men with shorter vacation time. However, comparisons in old age may have been diluted by higher mortality during follow-up among men with shorter vacation time. This is the first study that investigates the association between vacation time and later health outcomes in a socioeconomically homogenous cohort within a labour market system that does not have general socioeconomic differences in terms of vacation times.

There are only two previous studies about the frequency and duration of vacation and long-term health endpoints. Our results are in accordance with those from the Framingham study (women

Table 3

Health-related quality of life in old age in 2000 according to annual vacation time in 1974

\begin{tabular}{|c|c|c|c|c|c|}
\hline \multirow[t]{2}{*}{ RAND-36 scale } & \multicolumn{2}{|l|}{ Vacation } & \multicolumn{3}{|c|}{$P$-value for difference between groups } \\
\hline & $\begin{array}{l}\text { Vacation } \\
>21 \text { days, } n^{\text {a }}\end{array}$ & $\begin{array}{l}\text { Vacation } \leq \\
21 \text { days, } n^{\text {a }}\end{array}$ & Unadjusted & $\begin{array}{l}\text { Adjusted for age, work time, smoking, } \\
\text { alcohol use, and baseline group assignment }\end{array}$ & $\begin{array}{l}\text { Further adjusted } \\
\text { for BMI }\end{array}$ \\
\hline Physical functioning, mean & $76.4(22.5)$ & $75.0(24.2)$ & .60 & .81 & .93 \\
\hline Role physical & $67.2(38.4)$ & $66.1(38.6)$ & .65 & .95 & .77 \\
\hline Role mental & $76.7(34.8)$ & $72.1(36.2)$ & .01 & .10 & .31 \\
\hline Vitality & $67.8(20.8)$ & $65.5(22.6)$ & .10 & .10 & .16 \\
\hline Mental health & $80.7(17.7)$ & $79.0(18.0)$ & .07 & .09 & .11 \\
\hline Social functioning & $83.8(23.2)$ & $81.6(24.7)$ & .09 & .32 & .32 \\
\hline Bodily pain & $77.8(22.3)$ & $75.3(24.5)$ & .13 & .19 & .28 \\
\hline General health & $58.9(18.6)$ & $56.8(19.5)$ & .08 & .035 & .057 \\
\hline Physical summary score & $45.7(9.2)$ & $45.4(9.6)$ & .74 & .80 & .82 \\
\hline Mental summary score & $53.3(9.9)$ & $52.2(10.1)$ & .028 & .64 & .75 \\
\hline
\end{tabular}

Variables are mean (SD).

a Number varied between 1231 and 1144 among men with longer vacation and 418 and 387 among men with shorter vacation (98.8-91.7\% of respondents). 
[7]), and MRFIT (men [8]) where the frequency of annual vacations was associated with subsequent morbidity or mortality. However, we must be very careful when comparing different cohorts from different cultures and with different lifestyle. It is also possible that one longer annual vacation vs. shorter periods throughout the year may have different stress-relieving properties, but we are not aware of any comparative studies in this respect. Nevertheless, in our study mortality started to diverge clearly later than nine years as observed in MRFIT. This can be explained by the over two-fold higher mortality risk in the MRFIT cohort (11.2\% died during nine years) than in the HBS (4.5\% died during the first nine years of follow-up). Background factors may include higher smoking prevalence and more diverse socioeconomic status in MRFIT compared to that in HBS. Also differences between American and Finnish vacation culture and vacation pattern in the 1970 s may provide some explanation for differences in the findings.

The MRFIT investigators discussed various explanations for the higher mortality risk and speculated stress-relieving and social interaction promoting properties of vacation. Positive effects of vacation have also been suggested in short-term studies [1-3]. An alternative explanation would be that the men taking less vacation are psychologically more vulnerable and this was supported with a small follow-up study where shorter vacation was associated with more psychosomatic disease [9]. In our cohort, the men with less vacation had clearly worse SRH at baseline and tentative findings were observed in old age among survivors. But what is cause and effect? Is too little vacation and more work the reason for worse $\mathrm{SRH}$, or vice versa? On the other hand, there were no differences between vacation time and some factors often related to stress such as sleep time, heart rate, and alcohol consumption.

Strengths of our study include the socioeconomically homogenous cohort which was working at baseline and largely clinically healthy. Moreover, being unwell would probably lead to less work and more vacation and thus dilute the differences. The follow-up time was long and mortality ascertainment reliable from national registers. Limitations include that the magnitude of stress was not assessed with specific measurements. The length of vacation was asked only at baseline, but in Finnish culture vacation habits have been quite stable during the study period. The generalizability of the results is limited by the male-only cohort of the highest socioeconomic strata, and differences in vacation culture (frequency, duration, type) between countries. Also the working environment during the 1970s was obviously different from the situation today. The differences in the HRQoL in old age were only tentative after adjustments.

\subsection{Conclusion}

This long follow-up of middle-aged men suggested that taking less vacation is a marker of higher mortality risk up to old age. Although men with shorter vacation time may have intrinsic psychological properties placing them at higher risk of adverse health outcomes, the relationship between mortality and shorter vacation was independent of them.

\section{Disclosure of interest}

The authors declare that they have no competing interest.

\section{Acknowledgments}

Funding support was received from the Helsinki University Hospital [Valtion tutkimusrahoitus TYH2014 to T.E.S], plus Gustaf V o.Victoria Frimurarestiftekse [to T.E.S.], and the Academy of Finland [Grant Number 257239 to MBvB].

\section{References}

[1] Strauss-Blasche G, Reithofer B, Schobersberger W, Ekmekcioglu C, Marktl W Effect of vacation on health: moderating factors of vacation outcome. J Travel Med 2005;12:94-101.

[2] Greie S, Humpeler E, Gunga HC, et al. Improvement of metabolic syndrome markers through altitude specific hiking vacations. J Endocrinol Invest 2006:29:497-504.

[3] De Bloom J, Kompier M, Geurts S, de Weerth C, Taris T, Sonnetag S. Do we recover from vacation? Meta-analysis of vacation effects on health and wellbeing. J Occup Health 2009;51:13-25.

[4] Virtanen M, Heikkilä K, Jokela M, et al. Long working hours and coronary heart disease: a systematic review and meta-analysis. Am J Epidemiol 2012;176:586-96

[5] Bannai A, Tamakoshi A. The association between long working hours and health: a systematic review of epidemiological evidence. Scand J Work Environ Health 2014;40:5-18

[6] Kivimäki M, Jokela M, Nyberg ST, et al. Long working hours and risk of coronary heart disease and stroke: a systematic review and meta-analysis of published and unpublished data for 603,838 individuals. Lancet 2015;386:1739-46.

[7] Eaker ED, Pinsky J, Castelli WP. Myocardial infarction and coronary death among women: psychosocial predictors from a 20-year follow-up of women in the Framingham Study. Am J Epidemiol 1992;135:854-64.

[8] Gump BB, Matthews KA. Are vacations good for your health? The 9-year mortality experience after the multiple risk factor intervention trial. Psychosom Med 2000;62:608-12.

[9] Vaillant GE. Natural history of male psychological health. IV. What kinds of men do not get psychosomatic illness? Psychosom Med 1978;40:420-31

[10] Adler NE, Boyce T, Chesney MA, et al. Socioeconomic status and health: the challenge of the gradient. Am Psychol 1994;49:15-24.

[11] Rantanen KK, Strandberg AY, Pitkälä K, Tilvis R, Salomaa V, Strandberg TE. Cholesterol in midlife increases risk of Alzheimer's disease during an up to 43year follow-up. Eur Geriatr Med 2014;5:390-3.

[12] Strandberg TE, Salomaa V, Strandberg AY, et al. Cohort profile: The Helsinki Businessmen Study (HBS). Int J Epidemiol 2015. pii: dyv310 [Epub ahead of print].

[13] Bonsdorff M, Strandberg AY, von Bonsdorff ME, Törmäkangas T, Pitkälä KH, Strandberg TE. Working hours and sleep duration in midlife as determinants of health-related quality of life among older businessmen. Age Ageing 2017;46:108-12.

[14] Huohvanainen E, Strandberg AY, Stenholm S, Pitkälä KH, Tilvis RS, Strandberg TE. Association of self-rated health in midlife with mortality and old age frailty: a 26-year follow-up of initially healthy men. J Gerontol A Biol Sci Med Sci 2016;71:923-8

[15] Keys A, Aravanis C, Blackburn H, et al. Probability of middle-aged men developing coronary heart disease in five years. Circulation 1972;45: 815-28

[16] Aalto AM, Aro AR, Teperi J. RAND-36 as a measure of health-related quality of life. Reliability, construct validity and reference values in the Finnish general population. Helsinki, Finland: Stakes; 1999, Research Reports No. 101.

[17] Charlson ME, Pompei P, Ales KL, MacKenzie CR. A new method of classifying prognostic comorbidity in longitudinal studies: development and validation. J Chronic Dis 1987;40:373-83.

[18] Hays RD, Morales LS. The RAND-36 measure of health-related quality of life. Ann Med 2001;33:350-7 